\title{
New-Onset Mania Following Bariatric Surgery
}

\author{
Hitekshya Nepal ${ }^{1}$, Mukul Bhattarai ${ }^{2}$, and Erie T. Agustin ${ }^{1}$ \\ ${ }^{1}$ Department of Psychiatry and Behavioral Sciences, Southern Illinois University, Springfield, IL, USA \\ ${ }^{2}$ Department of Internal Medicine, Geisinger Medical Center, Danville, PA, USA
}

\begin{abstract}
Obesity has become a major public health problem over the past two decades. Non-surgical management of obesity does not often achieve its long term goals. Surgical treatment is roaring in popularity because of dramatic and durable results. However, outcomes from bariatric surgery have become a significant area of scrutiny because it is also associated with several medical and psychological complications. Out of those complications, there are descriptions of neuropsychiatric disorders and psycho-behavioral symptoms after surgery. Meanwhile, few reports of acute psychosis are described but to our knowledge, our case is the first case report of primary mania following bariatric surgery. We present an unusual and challenging case of primary mania in a 57 year old female who underwent bariatric surgery two months ago. Patient responded well initially to antipsychotic followed by mood stabilizer.

Psychiatry Investig 2015;12(1):152-154
\end{abstract}

Key Words Bariatric surgery, Mania, Psychosis, Morbid obesity.

\section{INTRODUCTION}

Obesity has been increasing rapidly as an epidemic and has become a major public health challenge around the globe. Severe obesity is associated with high levels of medical and psychiatric co-morbidities as well as increased mortality and medical expenditures. ${ }^{1}$ Non-surgical management of obesity does not often achieve its long term goals. Therefore, surgical treatment is roaring in popularity because of dramatic and durable results considering it as an "easy fix" for a complicated problem.

However, bariatric surgical outcomes have become a significant area of scrutiny because of its association with several medical and psychological complications. Out of those complications, neuropsychiatric disorders and psycho-behavioral symptoms after surgery are commonly described. During psychological evaluation of prebariatric surgery patients, it has been found that $66 \%$ have at least one axis I diagnosis, out of which mood disorders (15.6\%), anxiety (24\%) and binge eating $(16.3 \%)$ are common. ${ }^{2}$ Thus, the national institute of health (NIH) consensus panel has recommended comprehensive

Received: September 18, 2013 Revised: October 16, 2013

Accepted: October 16, 2013 Available online: January 12, 2015

$\triangle$ Correspondence: Hitekshya Nepal, MD

Department of Psychiatry and Behavioral Sciences, Southern Illinois University, 901 W Jefferson Street, Springfield, IL 62794, USA

Tel: +1-570-764-0092, Fax: +1-570-293-0140, E-mail: hitekshya@gmail.com

(c) This is an Open Access article distributed under the terms of the Creative Commons Attribution Non-Commercial License (http://creativecommons.org/licenses/by$\mathrm{nc} / 3.0$ ) which permits unrestricted non-commercial use, distribution, and reproduction in any medium, provided the original work is properly cited. pre-surgical multidisciplinary approach including psychiatric evaluation as part of the mandatory work up before bariatric surgery. But there is no definitive guideline for post bariatric psychiatry evaluation even if the literature demonstrates that post-surgical prevalence of psychiatric illnesses is equivocal with the pre-surgical ones. ${ }^{2}$ Meanwhile, few reports of acute psychosis are also described after the surgery, but to our knowledge, our case is the index case of primary mania following bariatric surgery.

\section{CASE}

A 57 year old morbidly obese female, weighing $412 \mathrm{lbs}$ $(186.88 \mathrm{~kg}$ ) with body mass index (BMI) of 59 had multiple comorbidities-hypertension, uncontrolled type II diabetes mellitus (HbA1c 9\%), dyslipidemia, polyarthritis and chronic pain. She underwent laparoscopic RouX en-Y gastric by-pass surgery with $150 \mathrm{~cm}$ antecolic Roux limb, subsequently losing $154 \mathrm{lbs}(70 \mathrm{~kg})$ in two months. She was apparently doing well until two months following surgery when she started complaining of episodic palpitations. Family also reported that she was acting "strange" which was described as refusing to eat or drink and withdrawing from social activities. She was drinking coffee more than usual. She presented to Emergency Department (ED) where routine lab tests including cardiac workup were unremarkable. Her palpitations were thought due to ingestion of large amount of coffee. She was then discharged from $\mathrm{ED}$ advising her to limit her caffeine intake. 
After a month, patient again presented to the ED with worsening of her symptoms. ED noted that review of symptoms was unremarkable except for insomnia and headache. She was found mildly dehydrated. Routine workup and Computerised tomography (CT) of head did not reveal any acute findings. She was hydrated in the ED and discharged home with primary care follow up.

After spending three days at home, patient presented to ED again with progression of her symptoms. Several family members accompanied the patient. Everybody reported that she had periods of clarity alternating with feeling irritable, throwing things and pouring water on herself. She was talking more than usual and not sleeping at all. Medical causes of cerebrovascular disease, infection, tumor, seizures and electrolyte imbalances, micronutrient deficiency were ruled out. After extensive review by general medicine and neurologist, no organic pathology was found. There was no history of drug and alcohol influence which was later confirmed by lab tests. On psychiatrist evaluation, patient was irritable, hostile but co-operative. She reported feeling "strange" on and off. She described "universal precautions to be taken during my stay at the hospital". She admitted that she had not been sleeping well but still appeared to be full of energy. Her mood was elevated and affect was congruent with mood. She admitted to have racing thoughts and felt that she was speaking more than usual with a loud voice. Patient also revealed that she was the most powerful and smart person in the city. The thought process was tangential with loosening of association. There was no suicidal or homicidal ideation. She was oriented to time, place and person. She denied any perpetual disturbances and any delusions, but she appeared to be a little guarded with some paranoid ideations (she repeatedly said her grandchildren were in danger from the mentally retarded children from her work place). Her insight and judgement were impaired.

The patient's daughter was interviewed separately who revealed that all these symptoms were completely new for her which started to occur about two months following gastric bypass surgery. Patient's past psychiatric history was unremarkable. Family history was unremarkable except for depression in her younger sister who was on antidepressants. Apparently, she had a good family support. She was completely fit for surgery from the psychologist evaluation prior surgery.

After comprehensive work up, it was felt that patient's current status likely revealed disturbances in her mood and affect which had occurred first time in her lifetime. After excluding all possibilities, the diagnosis of primary mania was made. She was started on ziprasidone $40 \mathrm{mg}$ twice daily which was increased to $80 \mathrm{mg}$ twice daily, and a mood stabilizer carbamazepine $200 \mathrm{mg}$ two times a day was added. The patient responded very well to these agents, and was discharged after seven days on ziprasidone $80 \mathrm{mg}$, carbamazepine $400 \mathrm{mg}$ both two times daily with outpatient psychotherapy three times a week. During three months follow up with our psychiatry department, the patient had complete resolution of her symptoms with normal mental status exam.

\section{DISCUSSION}

Emerging data supports bariatric surgery as an effective treatment of several comorbid conditions that accompany obesity despite its association with several medical and psychiatric adverse outcomes. ${ }^{4}$ When we describe about psychiatric problems associated with bariatric surgery, several neuropsychiatric disorders and psycho-behavioral symptoms have been described. ${ }^{5}$ The common non psychotic disorders associated with post bariatric surgery include depression, eating disorder and substance abuse. Frank eating disorders i.e. anorexia nervosa and bulimia nervosa, post-surgical eating avoidance disorder characterized by anxiety and disturbed eating have been reported. ${ }^{3,4}$ Reports of cases of addictive behavior like alcohol abuse, gambling, compulsive shopping, compulsive sexual behavior in patients who have undergone bariatric surgery have also been described. ${ }^{4}$ A number of authors have also described about the psychotic complications following bariatric surgery which are not the part of primary mania. ${ }^{6}$ The psychotic symptoms are often attributed as Wernicke-Korsakoff Psychosis (WKP), encephalopathy, psychotic episodes, delirium or pseudochorea. ${ }^{5-8}$ But there is lack of description of a manic episode or bipolar disorder following bariatric surgery since the time of beginning of bariatric surgery in 1950s although there are several cases of mood disorders reported in morbidly obese patients undergoing pre-surgical evaluation. ${ }^{2}$

New-onset mania in older adults is difficult to diagnose. ${ }^{10}$ Our patient presented to the ED two times without recognition of prodromal symptoms of mania. Furthermore, once mania is suspected, it is very important to rule out secondary mania in older adults which results from pharmacological, metabolic, or neurologic causes. In order to explain the symptomatology in our patient, several differential possibilities were considered including wide spectrum of causes of delirium, electrolytes disorder, hormonal imbalance, Central nervous system (CNS) infection, seizures, drug abuse, WKP versus primary psychosis versus mania. Other rare causes due to micronutrients deficiency as a result of bariatric surgery and new eating patterns leading to the acute changes in her mental status was thought initially but micro nutrient profile was within normal limits. The paraneoplastic panel was normal excluding any cancer affecting the nervous system. Rarely, general anaesthesia and laproscopic procedure causing "microbubbles" could be a possibility. ${ }^{8}$ But our patient underwent 
weight loss surgery two months prior to onset of symptoms and the surgery was uneventful and uncomplicated. Thus, the diagnosis of primary mania was made. Generally, manic episode is usually precipitated by underlying stressors and psychosocial problems. It is known that almost one fourth of manic episodes in bipolar disorder are precipitated by stressful situation or life events. However, in our patient we ruled out these risk factors of mania by thorough history from patient and collaterals. Moreover, our patient was psychologically clear when pre-screened for bariatric surgery.

No consensus has been reached with regard to the treatment of bouts of acute mania in the world. In a meta-analysis by Nivoli et al. report that monotherapy with atypical antipsychotics as a recommendation as a first choice in the treatment of acute mania as they have sedative properties and short term side-effect profile. ${ }^{9}$ Because of recently established efficacy of new antipsychotic agents and our own experience in the management of primary mania, we chose ziprasidone initially. Our patient responded very well to this atypical antipsychotic in the acute stage and to a mood stabilizer carbamazepine later also supports this diagnosis.

There are few cases in literature discussing on first episode of mania occurring in later years but not in post bariatric surgery patients. In well conducted studies, high prevalence rates of mood and anxiety disorders in general population have been revealed. ${ }^{2}$ For mood disorder, the life time prevalence rate is $45.5 \%$ and current prevalence rate is $15.6 \%$. $^{2}$ Among those, the life time prevalence rate of bipolar I or bipolar II disorder is $3.5 \%$ whereas the current prevalence rate of the same is $1.7 \% .^{2}$ If the reported life time prevalence rate of bipolar disorder is $3.5 \%$, then there could be a possibility of manic episode occurring after bariatric surgery could either be a natural recurrence of a manic episode or due to hitherto unknown mechanism during the postsurgical period. Or, this rare presentation may indicate a role of precipitation by a psychosocial stressor, probably due to surgery and weight loss. To conclude, it is important to recognize subtle symptoms of primary mania in a patient who has undergone recent bariatric surgery in order to avoid patient suffering and early commencement of an effective treatment. Establishing the guideline for psychological assessment to evaluate post bariatric surgery patient may be beneficial. Atypical antipsychotic such as ziprasidone followed by mood stabilizer such as carbamazepine are effective agents to treat this condition.

\section{REFERENCES}

1. Ogden CL, Carroll MD, Kit BK, Flegal KM. Prevalence of obesity in the United States, 2009-2010. NCHS Data Brief No. 2012;82:1-8.

2. Kalarchian MA, Marcus MD, Levine MD, Courcoulas AP, Pilkonis PA, Ringham RM, et al. Psychiatric disorders among bariatric surgery candidates, relationship to obesity and functional health status. AmJ Psychiatry 2007;164:328-334.

3. Scioscia TN, Bulik CM, Levenson J, Kirby DF. Anorexia nervosa in a 38 -year-old woman 2 years after gastric bypass surgery. Psychosomatics 1999;40:86-88.

4. Marcus MD, Kalarchian MA, Courcoulas AP. Psychiatric evaluation and follow-up of bariatric surgery patients. Am J Psychiatry 2009;166:285291.

5. Toth C, Voll C. Wernicke's encephalopathy following gastroplasty for morbid obesity. Can J Neurol Sci 2001;28:89-92.

6. Cirignotta F, Manconi M, Mondini S, Buzzi G, Ambrosetto P. WernickeKorsakoff encephalopathy and polyneuropathy after gastroplasty for morbid obesity: report of a case. Arch Neurol 2000;57:1356-1359.

7. Jiang W, Gagliardi JP, Raj YP, Silvertooth EJ, Christopher EJ, Krishnan KR. Acute psychotic disorder after gastric bypass surgery, differential diagnosis and treatment. Am J Psychiatry 2006;163:15-19.

8. Manapuram RK, Reddy Manne VG, and Larin KV. Phase-sensitive swept source optical coherence tomography for imaging and quantifying of microbubbles in clear and scattering media. J Appl Phys 2009;105: 102040.

9. Nivoli AM, Colom F, Murru A, Pacchiarotti I, Castro-Loli P, GonzálezPinto A, et al. Review new treatment guidelines for acute bipolar depression: a systematic review. J Affect Disord 2011;129:14-26.

10. Brooks JO 3rd, Hoblyn JC. Secondary mania in older adults. Am J Psychiatry 2005;162:2033-2038. 